IZA DP No. 5493

Putting Different Price Tags on the Same Health Condition: Re-evaluating the Well-Being Valuation Approach

Nattavudh Powdthavee

Bernard van den Berg

February 2011 


\title{
Putting Different Price Tags on the Same Health Condition: Re-evaluating the Well-Being Valuation Approach
}

\author{
Nattavudh Powdthavee \\ Nanyang Technological University \\ and IZA
}

Bernard van den Berg

CHE, University of York

\section{Discussion Paper No. 5493 \\ February 2011}

\author{
IZA \\ P.O. Box 7240 \\ 53072 Bonn \\ Germany \\ Phone: +49-228-3894-0 \\ Fax: +49-228-3894-180 \\ E-mail: iza@iza.org
}

Any opinions expressed here are those of the author(s) and not those of IZA. Research published in this series may include views on policy, but the institute itself takes no institutional policy positions.

The Institute for the Study of Labor (IZA) in Bonn is a local and virtual international research center and a place of communication between science, politics and business. IZA is an independent nonprofit organization supported by Deutsche Post Foundation. The center is associated with the University of Bonn and offers a stimulating research environment through its international network, workshops and conferences, data service, project support, research visits and doctoral program. IZA engages in (i) original and internationally competitive research in all fields of labor economics, (ii) development of policy concepts, and (iii) dissemination of research results and concepts to the interested public.

IZA Discussion Papers often represent preliminary work and are circulated to encourage discussion. Citation of such a paper should account for its provisional character. A revised version may be available directly from the author. 
IZA Discussion Paper No. 5493

February 2011

\section{ABSTRACT}

\section{Putting Different Price Tags on the Same Health Condition: Re-evaluating the Well-Being Valuation Approach}

Many recent writings in health policy have proposed that health be valued directly and in monetary terms using the new well-being valuation method. Yet there is currently no clear consensus on what the best measure of individual's experience may be for the evaluation process. To shed light on this issue, monetary values for a number of health problems are compared across different well-being measures within the same UK data set. We find that, while there is strong internal consistency of health impacts within each well-being measure, hugely different monetary valuations are obtained for the same health problem across different well-being measures. Our results, although should only viewed as illustrative, call for economists to rethink about which measure of well-being or experienced utility to be used in the well-being valuation method, should the approach ever be implemented in real policy contexts.

JEL Classification: $\quad \mathrm{H} 8, \mathrm{I} 18, \mathrm{I31}$

Keywords: well-being, compensation variations, monetary valuations, happiness, health, GHQ

Corresponding author:

Nattavudh Powdthavee

Division of Economics

School of Humanities \& Social Sciences

Nanyang Technological University

14 Nanyang Drive

Singapore, 637332

E-mail: n.powdthavee@ntu.edu.sg 


\section{Introduction}

Many recent writings in health policy have proposed that health be valued directly and in monetary terms using the recently proposed well-being valuation method. Yet there is currently no clear consensus within the literature on what the best measure of individual's experience may be for the evaluation process.

Our paper explores whether different measures of well-being produce similar values of monetary values of the same health condition. We present econometric evidence that the monetary values of the same health condition varies greatly across different well-being measures within the given data set. Our results suggest that economists may need to consider these differences in the monetary values of the same health condition before the well-being valuation method can be taken seriously in health, as well as in public policy.

More specifically, this paper documents evidence that:

(i) There is considerable internal consistency in the ordinal ranking of health conditions across different well-being measures, with depression often ranking first in terms of impact;

(ii) Measures of cognitive well-being such as life satisfaction generate significantly smaller values of health compensation for the same health condition than measures of affective well-being such as an individual's recent states of mental well-being, and measures of domain-specific well-being such as health satisfaction and self-assessed health compared to other people of the same age.

\section{Background}

Within the medical profession, the process of assigning monetary values to different health conditions is viewed as both controversial and unethical method in determining how much health care resource should be allocated for each patient. The idea that health conditions should be evaluated and ranked in terms of how much people are willing to pay in order to avoid them, or willing to pay for treatments to cure them, seems at odd 
when it is being viewed together with how an equitable health care system should be run (e.g., Hirt et al., 2000; Smith \& Richardson, 2005). It also weighs heavily against the common health care perception that every human life should have equal values (Cutler, 2002). Such concerns are reflected in the UK's National Institute for Health and Clinical Excellence's (NICE) recommendations that health benefits are to be measured in terms of gains in quality adjusted life years (QALYs) rather than basing them on people's willingness to pay.

Yet given the controversy surrounding the methods used to calculate monetary values to different health conditions, there appears to be an increasing tendency within the academic community to try and encourage health policy makers to value health directly in monetary terms (e.g., Diener et al., 1998; Klose, 1999; Ferrer-i-Carbonell \& Van Praag, 2002; Mentzakis, 2010). One of the main reasons for this is that monetary values of health enables direct and objective comparisons to be made between the relative benefits and costs of different treatments or interventions, thus making decisions about which conditions and treatments to prioritise easier for policy makers.

Despite this tendency, there is apparently no clear consensus on what the best relevant method of evaluation may be. At present, one of the most used approaches by economists is the revealed preference (RP) approach. Here, people's revealed preferences or behaviours in the market are used to derive values for different health conditions, e.g., by analysing health risk people are willing to take in exchange for higher wages. ${ }^{2}$ Despite its appeals - one being a clear objective indicator of individual's health preferences, there are a number of empirical limitations to this RP approach. For instance, the RP method does not easily allow for generalisation across different cases of health conditions, and a representative data can sometimes be very difficult to collect.

As a solution, the contingent valuation (CV) method, which is a survey-based hypothetical and direct method to elicit monetary valuations of effects of health

\footnotetext{
${ }^{2}$ For a comprehensive overview of the revealed and stated preference methods, see Kip-Viscusi (1993), Viscusi and Aidy (2003), Diener et al. (1998), Gyrd-Hansen (2003), Klose (1999), and Smith (2003).
} 
technologies and conditions (see, e.g., Tsuchiya \& Williams, 2001), had been adopted by many economists as an alternative approach to the RP method. By asking individuals to directly state their willingness to pay for treatments of a certain illness, or for inclusion of treatments in health insurance package, or on reimbursement list in case of national health system, the $\mathrm{CV}$ approach allows for easy generalisation across different health conditions of interest, while it is also cheap to collect on a large scale (Donaldson et al., 1995; Liu et al., 2000; Amin \& Khondoker, 2004).

It is, however, well-known that the CV method is not without serious biases of its own. First there is a substantial disparity between willingness to pay (WTP) and willingness to accept values in empirical studies (WTA). For example, it has been found that the WTA/WTP ratios vary from 2.5 to 2.9 (Brown, 2005). Although smaller differences have been reported in a health care application (Van den Berg et al., 2005), this disparity puts a serious question mark on the validity of $\mathrm{CV}$ responses, given that such a difference cannot be explained by income effects alone (Hanemann, 1991). One reason for this is because the $\mathrm{CV}$ method has been found to suffer from several cognitive biases such as loss aversion, the endowment effect, the focusing effect, and human's ability to adapt to different health conditions over time (see, Kahneman \& Tversky, 1979; Kartman et al., 1998; Dolan \& Kahneman, 2008). For example, one of the reasons why WTA is often different to WTP for the same good is because of the endowment effect, i.e. our tendency to value something more once ownership has already been established - simply because we tend to believe that the utility of a loss is greater than the utility of an equivalent gain (Kahneman et al., 1990). In the health framework, the compensation required to compensate a health loss (WTA) will tend to exceed the amount a person would pay for the equivalent gain in health which to participants seems to have lower utility values (O’Brien et al., 2002).

More recently, a new approach -- the well-being valuation (WV) method -- has been proposed within the economics literature as an alternative, and preferable, approach to both the RP and the CV methods when it comes to determining the different monetary valuations of health. The method involves taking a randomly-selected representative 
sample of individuals, asking them to self-rate their experiences such as their life satisfaction or their moment-to-moment happiness levels, and then use regression techniques to work out the implied 'shadow price' of different types of health problems, i.e. the additional income (on top of the household income) needed to be given to the individual to just compensate - no more, no less - for the well-being losses from acquiring a particular health condition. There is a growing acceptance of this method in the economics literature; it has been used, for example, to calculate monetary valuations for many of the occurrences in life that have no obvious market values. This includes, but not limited to, the values of marriage (Blanchflower \& Oswald, 2004), the extent of social network (Powdthavee, 2007a) and air quality (Luechinger, 2009), as well as the costs of marital separation (Clark \& Oswald, 2002), crime (Powdthavee, 2005; Moore \& Shepherd, 2006), a natural disaster (Luechinger \& Raschky, 2009), a death of loved ones (Oswald \& Powdthavee, 2007a), informal care (Van den Berg \& Ferrer-i-Carbonell, 2007), terrorism (Frey et al., 2009), airport noise (Van Praag \& Baarsma, 2005). With respect to health, two of the first economists to use the WV method to value different types of chronic conditions were Ferrer-i-Carbonell and Van Praag (2002). They estimated how much income is needed to compensate for the loss of well-being brought about by health conditions including diabetes, blood pressure problem, and migraine ${ }^{3}$. For more recent attempts, see Groot and Van den Brink (2004, 2006) and Groot et al (2004).

The main difference between the $\mathrm{WV}$ and the $\mathrm{CV}$ methods is that 'utility' is conceptualized differently between the two approaches. While the CV approach attempts to elicit people's willingness to pay through their stated preferences over different hypothetical situations, the WV approach argues that what really defines the impact of a health problem is not how we hypothesises it to be but the degree to which we attend to that condition in the experience of our lives (Dolan et al., 2009). For this reason, a more direct measure of people's experiences, one that does not draw people's attention too much towards the health condition in question - and therefore would suffer less from

\footnotetext{
${ }^{3}$ See Mentzakis (2010) for more recent estimates for the UK. The other paper that systematically examined the relationships between satisfaction levels and health problems is a paper by Groot (2000). Groot (2000) did not derive monetary values of health but derived QALY values for various chronic conditions.
} 
relevant scope and focusing effects than the $\mathrm{CV}$ approach, is required to assess the impact of health in monetary terms. ${ }^{4}$

While the discussion over whether or not we should be valuing health directly is taking off, one important question remains: Which measure of well-being should we use to assess the monetary values of health conditions? Currently there are many measures of experience in existence, and there is no general consensus on which measure should be the gold standard measure to be used in the WV literature. For example, while the most used measure of experienced utility in the well-being valuation approach is the life satisfaction scale (Blanchflower \& Oswald, 2004; Van Praag \& Baarsma, 2005; Powdthavee, 2007a), other scholars have also used other measures of well-being such as the General Health Questionnaire (GHQ-12) and health satisfaction as their quality of life variable (see, e.g., Ferrer-i-Carbonell \& Van Praag, 2002; Clark \& Oswald, 2002; Oswald $\&$ Powdthavee, 2008). Some even used measures of attitudes towards the experience in question, i.e. fear of crime (Moore \& Shepherd, 2006). Could these different measures generate consistent monetary values for the same health conditions? Our hypothesis is that it is unlikely that the monetary valuations of health conditions will be consistent across all well-being measures for at least two reasons: (1) both valuation questions intend to measure at least partly different concepts, and (2) income has been found to correlate more with measures of cognitive well-being - such as life satisfaction - than measures of affects - such as the GHQ-12 (Schwarz, Kahneman, \& Xu, 2008). In addition, Huppert and Whittington (2003) found that health and income may affect illbeing and well-being differently, considering that ill-being and well-being are two distinct dimensions and not opposite end of the same scale. Therefore, a natural empirical question is: To what extent do different experience measures produce different monetary valuations of the same health condition. To the best of our knowledge, no study has before done a direct comparison of monetary valuations of health between different measures of experiences.

\footnotetext{
${ }^{4}$ For a more detailed theoretical discussion of the WV method, see Kahneman et al. (1997), Kahneman and Sugden (2005), and Dolan and Kahneman (2008).
} 
This paper aims to contribute to the WV literature by examining the internal and external consistencies of the health impacts on different measures of experienced utility within the same dataset. We study the numbers that people report when asked about a) how satisfied they are with their life overall, b) their usual states of mental well-being, c) their health satisfaction, and d) their self-assessed health compared to other people their age. The four measures were selected on the basis that all had been studied extensively in either the well-being or health policy literature (see, for example, Oswald, 1997; Powdthavee, 2009).

While it may be clear on paper that these survey questions were constructed to elicit distinct aspects of well-being, less is known about the interplay between health and income across these quality of life measures for each individual in the data set. By definition, life satisfaction is constructed with an aim to elicit the respondent's past, present, and future global well-being (Diner et al, 1985). Measures of mental well-being are constructed to elicit the respondent's usual mental states such as whether the respondent loses sleep from worries or loses self-confidence during predefined recall period. Both health satisfaction and self-assessed health tap into the respondent's perception of his or her own overall health-related quality of life, although they are measured differently in the survey (not only the number of answering categories differ but also the reference point as the health satisfaction question asks individuals to rate their health, self-assessed health asks individuals to value their health against the health of other people from their age). The calculated monetary values of health will depend on how both health conditions and income variables enter each well-being equation. One hypothesis is that the monetary value of the same health condition will be higher in the mental well-being equation than in life satisfaction and subjective health equations, given that income is found to matter a lot less on an individual's current mental health state than on her assessment of overall life satisfaction (Kahneman et al., 2006).

Using the unique British panel data set, we estimate micro-econometric experience measure equations with various illnesses and disabilities as explanatory variables. We attempt to derive monetary values of health conditions by calculating how much extra 
income would be required to compensate for each health condition and per each wellbeing equation, which previous studies have not done before.

\section{Data}

The data set comes from the British Household Panel Survey (BHPS). This is a nationally representative of British households, containing over 10,000 adult individuals. The survey has been conducted between September and Christmas of each year from 1991 (Taylor et al., 2002).

This paper draws on two survey questions on subjective health problems in the BHPS. The first set of questions asks each individual in every wave of the BHPS to state which (but not limited to one) of the following thirteen health conditions (problems, illnesses or disabilities)he or she has, excluding temporary conditions:

1. Problems with arms, legs, and hands

2. Difficulty seeing

3. Difficulty hearing

4. Skin conditions/allergies

5. Chest/breathing problems

6. Problems with heart and blood pressure

7. Problems with stomach/kidney/liver

8. Diabetes

9. Nerves/anxiety/depression

10. Alcohol/drugs

11. Epilepsy

12. Migraine/chronic headache

13. Other

Although subjective in nature, the checklist of these health conditions has been shown to correlate well with GP reports (Kriegsman et al, 1996) and the use of health and welfare 
services (Sacker et al, 2003). People seem more likely to under-report their true health conditions in the absence of a list. There is also evidence that the inclusion of a checklist of conditions in the survey encourages reporting of illnesses by the genuinely ill and not by those who are less severely affected by their disease (Knight et al., 2001).

The second set of questions asks individuals about their physical functioning: "Does your health in any way limit (a) your daily activities and (b) amount or type of work compared to most people your age?"

In terms of well-being, we use four measures of experience previously used or discussed in the well-being valuation literature: (a) overall life satisfaction, (b) the usual states of mental well-being, (c) health satisfaction, and (d) self-assessed health. The questions of the first three measures appear in the self-completion section of the questionnaire, whereas the question on self-assessed health is asked face-to-face by an interviewer. The order of appearance is that self-assessed health is asked first as part of the face-to-face interview, then the usual states of mental well-being, health satisfaction, and then life satisfaction. Apart from the health satisfaction and the life satisfaction questions which are placed close to each other, the rest are allocated much further apart, with other questions slotted in between.

Responses to life satisfaction question are elicited using the following question: "All things considered, how satisfied or dissatisfied are you with your life overall using a 1-7 scale? 1 = very dissatisfied, ..., 7 = very satisfied".

The mental well-being score is derived from the General Health Questionnaire (GHQ-12) score. The scale is considered by many medical scholars and other researchers as a good proxy for mental stress and strain. Recent applications of GHQ include Cardozo et al (2000), Clark and Oswald (2002), Pevalin and Ermisch (2004), Robinson et al (2004), Oswald \& Powdthavee (2007b), and Powdthavee and Vignoles (2007). Individuals indicate on a 4-point scale from 1 (no more than usual) to 4 (much more than usual) how often over the past few weeks they had lost sleep over worry, felt constantly under strain, 
felt they could not overcome difficulties, been feeling unhappy and depressed, been losing confidence, and been feeling like a worthless person. Individuals were also asked to indicate on a 4-point scale from 1 (better than usual) to 4 (much less than usual) on how often over the past few weeks that had felt that they were playing a useful part in things, felt capable of making decisions, been able to enjoy day-to-day activities, been able to concentrate, been able to face up to problems, and been feeling reasonably happy. We use the Likert score of GHQ, which is the summation of all the responses to the GHQ questions. Put exactly, this is the BHPS variable HLGHQ1, with a scale running from 0 (best mental well-being) to 36 (worst mental well-being). However, for simplicity, we have decided to reverse the original HLGHQ1 coding so that the value of 0 represents the worst mental well-being and 36 is the best mental well-being.

The health satisfaction question has the following wordings: "How satisfied or dissatisfied are you with your health overall using a 1-7 scale? 1 = very dissatisfied, ..., $7=$ very satisfied".

Finally, self-assessed health is one of the most often used survey question to measure health (e.g., Contoyannis et al, 2004; Powdthavee, 2009). Exact wording in the BHPS is: "Please think back over the last 12 months about how your health has been. Compared to people of your own age, would you say that your health has on the whole been excellent, good, fair, poor, very poor?". The responses are coded so that $1=$ very poor health, $\ldots, 5=$ excellent health.

This study uses data from Waves 6-18 in the BHPS. However, we had to omit Waves 9, 11 and 14 from the analysis as they either do not contain a set of questions on health and life satisfactions, or the self-assessed health question was asked differently - i.e., not comparing against other peers of the same age group -- in these surveys. We restrict the sample to contain those of working age (16-65) with information on health conditions and the four measures of life experience. This yields an unbalanced panel of 104,537 observations (22,169 unique individuals). Of those, roughly $29 \%$ reported to have at least one listed health problem, and approximately $25 \%$ reported to have two or more. Around 
$14 \%$ said that their health has limited them from doing day-to-day activities, and $15 \%$ said that their health has limited the amount or type of work that they could do. Correlations among the four measures of life experience are moderate ranging from 0.35 to 0.66 . The smallest correlation coefficient $(=0.35)$ indicates the correlation between self-assessed health and life satisfaction, whilst the largest correlation coefficient $(=0.66)$ reflects the correlation between self-assessed health and satisfaction with health. A detailed summary of descriptive statistics is reported in Table 1.

\section{Empirical strategy}

Assume, as in Blanchflower and Oswald (2004), that there exists a generalized wellbeing function:

$W=r(u(h, y, z))+e$,

where $W$ denotes individual's well-being; the $u(.$.$) function is the respondent's true life$ experience or well-being and is observable only to the individual asked; $r($.$) is a non-$ differentiable function relating actual to reported well-being; $h$ represents health stock; $y$ denotes income; $z$ is a set of socio-demographic and personal characteristics; and $e$ is an error term that subsumes the inability of human beings to communicate accurately their levels of life experience. The true well-being $u(. .$.$) is assumed to be increasing and$ concave in both $h$ and $y$.

The monetary valuation of having a health condition on life experience or well-being can be determined by estimating the following empirical counterpart to equation (1)

$W_{i t}=H_{i t}^{\prime} \beta+\gamma Y_{i t}+X_{i t}^{\prime} \lambda+\varepsilon_{i t}, \quad i=1 \ldots N, t=1 \ldots T$,

where $W_{i t}$ is the well-being score, i.e., 1-7 on the life satisfaction and the satisfaction with health scales, 0-36 on the mental well-being or the inverse-GHQ scale, or 1-5 on the self 
assessed health scale; $H_{i t}^{\prime}$ contains a vector of health condition and problem dummies; $Y_{i t}$ is $\log$ of real equivalent household income (which is defined as the log of real household income/square of the number of people in the household); and $X_{i t}^{\prime}$ are other standard controls in experience or well-being equations, including dummies for gender, age, agesquared, marital status, education dummies, employment dummies, number of dependent children, region and year (see, e.g., Blanchflower and Oswald, 2004). In order to account for individual unobserved components, we also introduce individual random effects into the equation. Hence, the error term can be decomposed to the individual random effect component, $\eta_{i}$, and the time-varying component, $v_{i t}$, as follows:

$\varepsilon_{i t}=\eta_{i}+v_{i t}$

Following Ferrer-i-Carbonell and Van Praag (2004), we decompose the explanatory variables of interest - in this case, health problems and income - into their mean over the observation period and the deviation from that mean as follows:

$$
\begin{aligned}
& H_{i t}^{\prime}=\bar{H}_{i}^{\prime}+\left(H_{i t}^{\prime}-\bar{H}_{i}^{\prime}\right), \\
& Y_{i t}=\bar{Y}_{i}+\left(Y_{i t}-\bar{Y}_{i}\right),
\end{aligned}
$$

Introduction of the mean variables helps to correct for the unobserved correlation between the individual random effects and the explanatory variables of interest; see Mundlak (1978). We can also interpret the addition of the mean variables as a way to decompose both health and income into a level and a shock effects. Equation (2) becomes

$$
W_{i t}=H_{i t}^{\prime} \beta+\bar{H}_{i t}^{\prime} \theta+\gamma Y_{i t}+\delta \bar{Y}_{i t}+X_{i t}^{\prime} \lambda+\varepsilon_{i t} .
$$

Here, the relevant income effects are given by:

$$
\gamma Y_{i t}+\delta \bar{Y}_{i t}=\gamma\left(Y_{i t}+\bar{Y}_{i t}\right)+(\gamma+\delta) \bar{Y}_{i t}
$$


The coefficient $\gamma$ is the shock effect and $(\gamma+\delta)$ is the level effect. As in Ferrer-iCarbonell and Van Praag (2002), we will use the level effect of income - which is taken to be the individual's permanent income - to calculate the monetary valuations or the implied shadow price of the level effect of each health condition, i.e. $\beta+\theta$. This implied shadow price, by definition, is equivalent to the extra income required to keep the person with a particular health condition at the same level of well-being. Given that the income variable in the well-being equations is in a log form, the shadow price formula for a person with a blood pressure problem, $H_{i t}^{\text {blood }}$, can be written as:

$$
\begin{aligned}
& \ln (S P+y)=\ln y \times \frac{\beta^{\text {blood }}+\theta^{\text {blood }}}{\gamma+\delta}, \\
& S P=y \times\left(\exp \frac{\beta^{\text {blood }}+\theta^{\text {blood }}}{\gamma+\delta}-1\right),
\end{aligned}
$$

where $S P$ is the calculated shadow price (or how much extra money is required to compensate an average person with a blood pressure problem), and $y$ is the average level of real household income per capita. Thus, an individual with a blood pressure problem, i.e. $H_{i t}^{\text {blood }}=1$, and an income of $y+S P$ will have the same level of well-being as an individual with no blood pressure problem and an income of $y$. The unit of these valuations is in pound sterling. One objection with this regression method is that cardinality is assumed for all of our measures of experienced utility. Nevertheless, as in Frey and Stutzer (2000), Frijters and Ferrer-i-Carbonell (2004), Luttmer (2005), and Powdthavee (2009), it makes virtually no different to the magnitudes of the coefficients, the trade-offs between estimated coefficients and the statistical significance of the final outcomes whether one assumes ordinality or cardinality in the well-being data. Therefore, for ease of interpretation, we adopt the same method as previous studies and estimate the models using only generalized least squares with random effects. ${ }^{5}$

\footnotetext{
${ }^{5}$ We are aware that a linear model may lead to an overestimation of the overall average SP values of the health problems, and a more generalized method may be preferred to the more standard approaches here (Mentzakis, 2010). Yet in order to make the interpretation of the SP values easy and generally applicable
} 


\section{Results}

Table 2 reports the life satisfaction, mental well-being, health satisfaction, and self assessed health equations random effects estimates. As would be expected, the health problems enter each well-being equation in a negative manner. In terms of statistical significance, the models seem to produce qualitatively similar results. With respect to health shocks, only 'epilepsy' is not significant in life satisfaction or in mental health, but significant in health satisfaction and self assessed health.

However, it is not straightforward to compare the magnitudes of the coefficients across equations, given the differences in scales across the four well-being measures. Nevertheless, it is still possible to work out the internal rankings of the level effects of health problems and conditions $(\beta+\theta)$ and compare them across well-being measures i.e. comparing the ordinal ranking of the size of the coefficients within each well-being regression equation.

Perhaps expectedly, 'depression and anxiety' ranks very highly in all of the well-being equations, coming up first in two of the four well-being measures. On the contrary, whilst there is a sizeable correlation between 'alcohol or drug related problems' and both life satisfaction and mental well-being, the same health problem only ranks eleventh and eight in the health satisfaction and self assessed health equations. What this implies is that some health problems correlate more with our overall well-being than our subjective health status. It is also worth noting that 'other health problems not listed' also ranks relatively high in all models, although we do not know what constitute these other health problems, i.e. we do not know whether they are mental or physical by nature.

Despite some notable differences, we find the correlations between how health impacts are ranked internally to be positive and sizeable across different well-being measures. For

for policy makers to implement if and when the WV methods are formally employed, the standard linear approach is preferred here in our descriptive analysis. 
example, the lowest correlation coefficient is between life satisfaction and self-assessed health $(=0.654)$, whilst the highest correlation coefficient is between health satisfaction and self-assessed health $(=0.936)$. The correlation coefficient between life satisfaction and mental well-being is approximately 0.9 (see the bottom of Table 3 ).

This relatively stable internal ranking represents an important finding in health policy in that the various measures of life experience could all be used to derive a consistent ranking of the impacts of health conditions on people's quality of life. This is primarily because the ability to produce a valid ordinal ranking of health problems could prove useful when it comes to making reimbursement decisions in health policy.

Whilst consistency in the internal rankings across different well-being measures provides some comforts for the advocates of the WV approach, it is thought that the estimated monetary values of health will be even more appealing to policy makers as they would enable objective comparisons between costs and potential benefits of investments in health care to be made. Using the formula provided in equation (8), Table 4 moves on to calculate the estimated monetary values of health problems and conditions.

To many, the $S P$ reported in Table 4 may be hard to grasp, as well as difficult to imagine them to ever be formally implemented in real life. For example, in order to compensate an average individual with a health problem connected with arms, legs, hand, feet, back, etc., so that she reports the same level of health satisfaction as someone who does not have the same health problem, an additional pay of $£ 9.79 \mathrm{E}+06$ (over $£ 9$ million) is required. However, in order to compensate the same average person for the same health problem so that she reports the same level of life satisfaction as someone who does not possess the same health condition, only $£ 7,000$ is considered a sufficient compensation package. Only a few health problems share similar $S P$ values, e.g. $£ 5,000-£ 6,000$ are needed to compensate an average individual for a drop in life satisfaction and mental well-being from having skin conditions/allergies, and $£ 3,000-£ 6,000$ are required to restore an average person's life satisfaction and mental well-being from diabetes. Moreover, we could see that the $S P$ values are often significantly smaller when they had 
been produced in the equation where life satisfaction is the dependent variable, and very high $S P$ values are generally observed in the equation where health satisfaction is the dependent variable. Such quantitative differences naturally lead to the question: Which well-being measure policy makers should be using if the WV approach is to be taken seriously in a policy context? The differences are made even clearer in Table 5 when we compare the supposedly objectively-comparable $S P$ values across different well-being measures. Of the ten highest $S P s$, nine of them were obtained from running the health satisfaction equation. By contrast, the bottom ten $S P \mathrm{~s}-$ ranking from $50^{\text {th }}$ to $60^{\text {th }}-$ include eight from the life satisfaction equation, thus confirming that there are significant quantitative differences in terms of the monetary valuation of the same health condition across different well-being measures.

\section{Discussions and conclusions}

A few questions suggest themselves.

First, what explains why such a significant difference in $S P$ of the same health condition exists? One natural explanation for this is that there is considerable heterogeneity in the effects of health problems across different well-being measures. Health conditions that are related to mental health appear to have large influences on (or rather significant correlations with) measures of overall well-being such as life satisfaction and mental well-being, whilst health conditions that are more physical and probably more salient to the health state of the individuals - e.g., health limits daily activities, as well as amount and type of work - seem to have produced larger negative coefficients in both health satisfaction and self-assessed health equations. What this implies is that when people are asked to evaluate their subjective health status, they tend to focus more of their attention on the physical conditions than their mental state of health. By contrast, problems with mental health are probably built into people's subjective evaluation of the overall quality of life such as life satisfaction and mental well-being. This is consistent with the theory on focusing effect, which states that people will often exaggerate the impact of any experience on their well-being, particularly if the question prompts them to do so 
(Schkade \& Kahneman, 1998). Given that physical health problems are easily observed and distinctively different to not having them, it is perhaps not surprising that more weights will be given to these conditions in the overall judgments of how healthy we feel compared to how we feel our life is going. By contrast, money, which is normally less salient compared to other factors in our lives whenever we are asked to think about our overall life satisfaction, will be even less distinct and more likely to be excluded from the subjective assessments of health satisfaction and health compared to other people our age. The same may also apply to the current state of mental well-being when it is compared to how income normally enters life satisfaction equations (Kahneman et al., 2006). In other words, the ratios between the size of the income coefficients and that of the health problems may vary a great deal across measures of well-being (for instance, the estimated $S P$ s obtained from the life satisfaction equation will tend to be small not because health problems have smaller impacts on the overall judgment of life satisfaction, but simply because the denominator in the eq. (8) - i.e. the sum of the two income coefficients - is large).

In short, it may be the case that the SPs of health problems will be overestimated in health satisfaction, self-assessed health, and possibly the mental well-being equations, whilst underestimated in the life satisfaction equation.

The second, and more pragmatic, question is: If the WV approach is to be taken seriously by policy makers, which measure of well-being (or experienced utility, as defined by Kahneman and co.) should we use? The results of this article suggest that if the ordinality of health impacts is the only thing we care about in health policy, then it will not matter much which well-being measure is adopted in the calculation of the ranking of each health impact. Yet if monetary valuations (or cardinalization) of different health conditions is preferred to the ordinal approach of health evaluation, then it is perhaps more feasible and theoretically reasonable to argue for the adoption of life satisfaction as the main well-being measure to be used in the WV approach. One reason for this is because, apart from the SPs of depression and alcohol/drugs-related problems, the estimated figures for other health problems make practical sense as in one can imagine 
them being allocated to patients in reality, e.g. $£ 8,000$ compensation for having heart/blood pressure problems per year. Another reason is that the theory behind life satisfaction is generally assessed by individuals as their 'total' or global well-being is technically sound (Diener et al., 1985). Given that health (or public) policy should be aimed at improving people's overall quality of life, life satisfaction scale has the required propriety with which policies could be formed upon. The second option would be the use of mental well-being measure, which is the GHQ-12 in our case, whilst the last choice would be health satisfaction.

In conclusion, although the idea that health conditions should be monetized is often viewed by clinicians and health policy makers as deeply controversial, a recent advancement in the well-being literature has sparked a new discussion among health economists, in particularly that of a relatively unbiased approach of calculating monetary values of different health conditions. However, despite the recent surge of interest on the new evaluation method, relatively little has been discussed within the well-being literature over which measure of well-being should be used in the WV approach. This paper was written to fill that research void. It essentially showed that we can often obtain different monetary valuations for the same health condition just by changing the dependent variable in the well-being equations. Frequently, the monetary values of the same health condition are smaller when life satisfaction, or a measure of our cognitive well-being, is used instead of other more affective or domain-specific measures of wellbeing. Our results suggest that economists and policy makers may need to consider seriously about these differences in the well-being construct before advising on which measure to be used in the WV approach, should it ever be implemented in real policy contexts.

Like all other papers in social sciences, the current article is not without limitations. One major criticism is that both income and health are endogenous in all of the estimated well-being regressions. While we could argue that the influences of the endogeneity bias on well-being estimates are probably the same across all well-being measures, we realize 
that it might not be the case in reality. Future research should therefore return to instrument for both health and income in each of the tested well-being equation. 


\section{References}

Amin, M., Khondoker, F. (2004). A contingent valuation study to estimate the parental willingness-to-pay for childhood diarrhoea and gender bias among rural households in India, Health Research Policy and Systems, 2:3.

Blanchflower, D.G., Oswald, A.J. (2004). Well-being over time in Britain and the USA, Journal of Public Economics, 88, 1359-1386.

Brown, T.C. (2005). Loss aversion without the endowment effect, and other explanations for the wta-wtp disparity. Journal of Economic Behavior \& Organization, 57, 367-379.

Clark, A.E., Oswald, A.J. (2002). A simple statistical method for measuring how life events affect happiness, International Journal of Epidemiology, 31, 1139-1144.

Contoyannis, P., Jones, A.M., Rice, N. (2004). The dynamics of health in the British Household Panel Survey, Journal of Applied Econometrics, 19, 473-503.

Cutler D.M. (2002). Equality, efficiency, and market fundamentals: the dynamics of international medical-care reform. Journal of Economic Literature, 40: 881-906.

Diener, E., Emmons, R.A., Larsen, R.J., Griffin, S. (1985. The satisfaction with life scale, Journal of Personality Assessment, 49, 71-75.

Diener, A., O’Brien, B., Gafni, A. (1998). Health care contingent valuation studies: a review and classification of the literature. Health Economics, 7, 313-326.

Dolan, P., Lee, H., King, D., Metcalfe, R. (2009). Valuing health directly. British Medical Journal, 339, 371-373.

Donaldson, C., Shackley, P., Abdalla, M., Miedzybrodzka, Z. (1995). Willingness to pay for antenatal carrier screening for cystic fibrosis, Health Economics, 4, 439-452.

Ferrer-i-Carbonell, A., Van Praag, BMS. (2002). The subjective costs of health losses due to chronic diseases. An alternative model for monetary appraisal. Health Economics, 11, 709-722.

Frey, B.S., Luechinger, S., Stutzer, A. (2009). The life satisfaction approach to valuing public goods: the case of terrorism, Public Choice, 138, 317-345.

Frey, B.S., Stutzer, A. (2000). Happiness, economy and institutions, Economic Journal, $110,918-938$. 
Frijters, P., Ferrer-i-Carbonell, A. (2004). How important is methodology for the estimates of the determinants of happiness?, Economic Journal, 114, 641-659.

Groot, W. (2000). Adaptation and scale of reference bias in self-assessments of quality of life, Journal of Health Economics, 19, 403-420.

Groot, W., Van den Brink, H.M. (2004). A direct method for estimating the compensation variation for severe headache and migraine, Social Science \& Medicine, 58, 305-314.

Groot, W., Van den Brink, H.M. (2006). The compensating income variation of cardiovascular disease, Health Economics, 19, 403-420.

Groot, W., Van den Brink, H.M., Plug, E. (2004). Money for health: the equivalent variation of cardiovascular diseases, Health Economics, 13, 859-872.

Gyrd-Hansen, D. (2003). Willingness to pay for a QALY, Health Economics, 12, 10491060.

Hanemann, W.M. 1991. Willingness to pay and willingness to accept: how much can they differ? American Economic Review, 81, 635-647.

Huppert, F.A., Whittington, J.E. (2003). Evidence for the independence of positive and negative well-being: Implications for quality of life assessment, British Journal of Health Psychology, 8, 107-122.

Kahneman, D., Knetsch, J.L., Thaler, R.H. (1990). Experimental tests of the endowment effect and the coarse theorem, Journal of Political Economy, 98, 1325-1348.

Kahneman, D., Krueger, A.B., Schkade, D., Schwarz, N, Stone, A.A. (2006). Will you be happier if you were richer? A focusing illusion, Science, 30, 1908-1910.

Kahneman, D., Sugden, R. (2005). Experienced Utility as a Standard of Policy Evaluation, Environmental \& Resource Economics, 32(1), 161-181.

Kahneman, D., Tversky, A. (1979). Prospect theory: an analysis of decision under risk, Econometrica, 47, 263-291.

Kahneman, D, Wakker, P.P. , Sarin, R. (1997). Back to Bentham? Explorations of Experienced Utility, Quarterly Journal of Economics, 112(2), 375-405.

Kartman, B., Stålhammer, N-O., Johannesson, M. (1998). Valuation of health changes with the contingent valuation method: A test of scope and question of order effects, Health Economics, 5, 531-541. 
Kip-Viscusi, W. (1993). The value or risks to life and health. Journal of Economic Literature, 31, 1912-1946.

Klose T. (1999). The contingent valuation method in health care. Health Policy, 47, $97-$ 123.

Knight, M., Stewart-Brown, S., Fletcher, L. (2001). Estimating health needs: The impact of a checklist of conditions and quality of life measurement on health information derived from community surveys. Journal of Public Health Medicine, 23(3), 179-186.

Kriegsman, D.M., Penninx, B.W., van Eijk, J.T., Boeke, A.J., Deeg, D.J. (1996). Selfreports and general practitioner information on the presence of chronic diseases in community dwelling elderly. Journal of Clinical Epidemiology, 49(12), 1407-1417.

Liu, J-T, Hammitt, J.K., Wang, J-D, Liu, J-L. (2000). Mother's willingness to pay for her and her child's health: a contingent valuation study in Taiwan, Health Economics, 9, 319326.

Luechinger, S.(2009). Valuing air quality using the life satisfaction approach, Economic Journal, 119, 482-515.

Luechinger, S., Raschky, P.A. (2009). Valuing flood disasters using the life satisfaction approach, Journal of Public Economics, 93, 620-633.

Luttmer, E.F.P. (2005). Neighbors as negatives: Relative earnings and well-being, Quarterly Journal of Economics, 120, 963-1002.

Mentzakis, E. (2010). Allowing for heterogeneity in monetary subjective well-being valuations. Health Economics, forthcoming.

Moore, S.; Shepherd, J.P. (2006). The cost of fear: Shadow pricing the intangible costs of crime, Applied Economics, 38, 293-300.

Mundlak, Y. (1978). On the pooling of time-series and cross-section data, Econometrica, 46, 69-85.

O’Brien, B.J., Gertsen, K., Willam, A.R., Faulkner, L.A. (2002). Is there a kink in consumers' threshold value for cost-effectiveness in health care? Health Economics, 11, 175-180.

Oswald, A.J. (1997). Happiness and Economic Performance, Economic Journal, 107, 1815-1831. 
Oswald, A.J.; Powdthavee, N. (2007). Obesity, unhappiness, and the challenge of affluence: Theory and evidence, Economic Journal, 117, 441-454.

Oswald, A.J.; Powdthavee, N. (2008). Death, happiness, and the calculation of compensatory damages, Journal of Legal Studies, 37(S2), S217-S252.

Pevalin, D.J.; Ermisch, J. (2004). Cohabiting unions, repartnering and mental health, Psychological Medicine, 34, 1553-1559.

Powdthavee, N. (2005). Unhappiness and crime: evidence from South Africa, Economica, 72, 531-547.

Powdthavee, N. (2008). Putting a price tag on friends, relatives, and neighbours: Using surveys of life satisfaction to value social relationships, Journal of Socio-Economic, 37, 1459-1480.

Powdthavee, N. (2009). Ill-health as a household norm: Evidence from other people's health problems, Social Science \& Medicine, 68, 251-259.

Powdthavee, N.; Vignoles, A. (2008). Mental health of parents and life satisfaction of children: A within-family analysis of intergenerational transmission of well-being, Social Indicators Research, 88, 397-422.

Robinson, K.L., McBeth, J.; MacFarlane, G.J. (2004). Psychological distress and premature mortality in the general population: A prospective study, Annals of Epidemiology, 14, 467-472.

Sacker, A., Wiggins, R.D., Clarke, P., Bartley, M. (2003). Making sense of symptom checklists: A latent class approach to the first 9 years of the British Household Panel Survey. Journal of Public Health Medicine 25(3), 215-222.

Schkade, D.A., Kahneman, D. (1998). Does living in California make people happy? A focusing illusion in judgment of life satisfaction. Psychological Science, 9, 340-346.

Smith, R.D. (2003). Construction of the contingent valuation market in health care: a critical assessment, Health Economics, 12, 609-628.

Smith, R.D., Richardson, J. (2005). Can we estimate the 'social' value of a QALY? Four core issues to resolve, Health Policy, 74, 77-84.

Tsuchiya, A., Williams, A. (2001). Welfare economics and economic evaluation. In: Economic evaluation in health care: merging theory with practice (eds: Drummond, M.F., McGuire, A.). Oxford University Press, 27-28. 
Van den Berg, B., Bleichrodt, H., Eeckhoudt, L. (2005). The economic value of informal care: a study of informal caregivers' and patients' willingness to pay and willingness to accept for informal care. Health Economics, 14, 363-376.

Van den Berg, B., Ferrer-i-Carbonell, A. (2007). Monetary valuation of informal care: the well-being valuation method, Health Economics, 16, 1227-1244.

Van Praag, B.M.S, Baarsma, B. (2005) Using happiness surveys to value intangibles: the case of airport noise. Economic Journal, 115, 224-246.

Viscusi, W.K., Aldy, J.E. (2003). The value of a statistical life: A critical review of market estimates throughout the world. Journal of Risk and Uncertainty, 27, 5-76. 
Table 1: Descriptive Statistics: BHPS, 1996-2008

\begin{tabular}{lccc}
\hline & M & SD & Range \\
\hline Life satisfaction & 5.16 & 1.25 & $1-7$ \\
Inverse GHQ (mental well-being) & 24.75 & 5.58 & $0-36$ \\
Satisfaction with health & 5.00 & 1.55 & $1-7$ \\
Self-assessed health & 3.87 & 0.92 & $1-5$ \\
Ln(real equivalent household income) & 9.56 & 0.72 & $-1.00-13.36$ \\
Problems connected with: arms, legs, hand, feet, back, etc. & 0.22 & 0.41 & $0-1$ \\
Difficulty in seeing (other than needing glasses to read) & 0.03 & 0.18 & $0-1$ \\
Difficulty in hearing & 0.05 & 0.22 & $0-1$ \\
Skin conditions/allergies & 0.13 & 0.33 & $0-1$ \\
Chest/breathing problems, asthma, bronchitis & 0.12 & 0.33 & $0-1$ \\
Heart/blood pressure or blood circulation problems & 0.11 & 0.31 & $0-1$ \\
Stomach/liver/kidneys or digestive problems & 0.07 & 0.25 & $0-1$ \\
Diabetes & 0.02 & 0.15 & $0-1$ \\
Depression, anxiety & 0.08 & 0.27 & $0-1$ \\
Alcohol or drug related problems & 0.01 & 0.07 & $0-1$ \\
Epilepsy & 0.01 & 0.09 & $0-1$ \\
Migraine or frequent headaches & 0.09 & 0.29 & $0-1$ \\
Other health problems not listed & 0.04 & 0.21 & $0-1$ \\
Health limits daily activities & 0.14 & 0.34 & $0-1$ \\
Health limits amount or type of work & 0.15 & 0.36 & $0-1$ \\
\hline & & & \\
Dof & 0.37 \\
\hline
\end{tabular}

Note: $\mathrm{N}=104,537$. 
Table 2: Random Effects Well-Being Regression Estimates: BHPS 1996-2008

\begin{tabular}{|c|c|c|c|c|}
\hline & $\mathbf{L S}$ & IGHQ & HS & SAH \\
\hline \multicolumn{5}{|l|}{ Health shocks, i.e. current health problems } \\
\hline \multirow[t]{2}{*}{ Problems connected with: arms, legs, hand, feet, back, etc. } & -0.035 & -0.253 & -0.246 & -0.175 \\
\hline & {$[0.011]^{* *}$} & {$[0.051]^{* *}$} & {$[0.012]^{* *}$} & {$[0.007]^{* *}$} \\
\hline \multirow[t]{2}{*}{ Difficulty in seeing (other than needing glasses to read) } & -0.060 & -0.155 & -0.057 & -0.057 \\
\hline & {$[0.020]^{* *}$} & [0.096] & {$[0.023]^{*}$} & {$[0.014]^{* *}$} \\
\hline \multirow[t]{2}{*}{ Difficulty in hearing } & -0.079 & -0.178 & -0.065 & -0.050 \\
\hline & {$[0.021]^{* *}$} & {$[0.101]+$} & {$[0.024]^{* *}$} & {$[0.014]^{* *}$} \\
\hline \multirow[t]{2}{*}{ Skin conditions/allergies } & -0.039 & -0.031 & -0.022 & -0.036 \\
\hline & {$[0.013]^{* *}$} & {$[0.062]$} & {$[0.015]$} & {$[0.009] * *$} \\
\hline \multirow[t]{2}{*}{ Chest/breathing problems, asthma, bronchitis } & -0.047 & -0.280 & -0.233 & -0.197 \\
\hline & {$[0.016]^{* *}$} & {$[0.074]^{* *}$} & {$[0.018]^{* *}$} & {$[0.011]^{* *}$} \\
\hline \multirow[t]{2}{*}{ Heart/blood pressure or blood circulation problems } & -0.048 & -0.368 & -0.277 & -0.229 \\
\hline & {$[0.015]^{* *}$} & {$[0.072]^{* *}$} & {$[0.017]^{* *}$} & {$[0.010]^{* *}$} \\
\hline \multirow[t]{2}{*}{ Stomach/liver/kidneys or digestive problems } & -0.056 & -0.327 & -0.333 & -0.271 \\
\hline & {$[0.016]^{* *}$} & {$[0.075]^{* *}$} & {$[0.018]^{* *}$} & {$[0.011]^{* *}$} \\
\hline \multirow[t]{2}{*}{ Diabetes } & -0.101 & -0.242 & -0.332 & -0.281 \\
\hline & {$[0.038]^{* *}$} & [0.181] & {$[0.044]^{* *}$} & {$[0.026]^{* *}$} \\
\hline \multirow[t]{2}{*}{ Depression, anxiety } & -0.473 & -3.930 & -0.514 & -0.355 \\
\hline & {$[0.015]^{* *}$} & {$[0.072]^{* *}$} & {$[0.018]^{* *}$} & {$[0.010]^{* *}$} \\
\hline \multirow[t]{2}{*}{ Alcohol or drug related problems } & -0.237 & -1.519 & -0.211 & -0.163 \\
\hline & {$[0.053]^{* *}$} & {$[0.253]^{* *}$} & {$[0.062]^{* *}$} & {$[0.036]^{* *}$} \\
\hline \multirow[t]{2}{*}{ Epilepsy } & -0.038 & -0.156 & -0.200 & -0.161 \\
\hline & {$[0.073]$} & [0.347] & {$[0.084]^{*}$} & {$[0.050]^{* *}$} \\
\hline \multirow[t]{2}{*}{ Migraine or frequent headaches } & -0.096 & -0.619 & -0.125 & -0.121 \\
\hline & {$[0.015]^{* *}$} & {$[0.071]^{* *}$} & {$[0.017]^{* *}$} & {$[0.010]^{* *}$} \\
\hline \multirow[t]{2}{*}{ Other health problems not listed } & -0.086 & -0.577 & -0.458 & -0.356 \\
\hline & {$[0.017]^{* *}$} & {$[0.080]^{* *}$} & {$[0.019]^{* *}$} & {$[0.011]^{* *}$} \\
\hline \multicolumn{5}{|l|}{ Average health problems over time } \\
\hline \multirow[t]{2}{*}{ Problems connected with: arms, legs, hand, feet, back, etc. } & -0.022 & -0.101 & -0.223 & -0.108 \\
\hline & [0.027] & [0.111] & {$[0.029]^{* *}$} & {$[0.016]^{* *}$} \\
\hline \multirow[t]{2}{*}{ Difficulty in seeing (other than needing glasses to read) } & -0.066 & -0.473 & -0.142 & -0.031 \\
\hline & [0.054] & {$[0.223]^{*}$} & {$[0.059]^{*}$} & [0.032] \\
\hline \multirow[t]{2}{*}{ Difficulty in hearing } & 0.025 & -0.050 & -0.081 & -0.031 \\
\hline & [0.041] & {$[0.173]$} & {$[0.045]+$} & [0.024] \\
\hline \multirow[t]{2}{*}{ Skin conditions/allergies } & -0.003 & -0.053 & -0.088 & -0.023 \\
\hline & [0.028] & [0.115] & {$[0.030]^{* *}$} & [0.016] \\
\hline \multirow[t]{2}{*}{ Chest/breathing problems, asthma, bronchitis } & -0.047 & -0.071 & -0.116 & -0.083 \\
\hline & {$[0.028]+$} & {$[0.118]$} & {$[0.031]^{* *}$} & {$[0.017]^{* *}$} \\
\hline \multirow[t]{2}{*}{ Heart/blood pressure or blood circulation problems } & -0.017 & -0.035 & -0.171 & -0.063 \\
\hline & [0.031] & {$[0.130]$} & {$[0.034]^{* *}$} & {$[0.018]^{* *}$} \\
\hline \multirow[t]{2}{*}{ Stomach/liver/kidneys or digestive problems } & -0.182 & -0.823 & -0.322 & -0.184 \\
\hline & {$[0.038]^{* *}$} & {$[0.157]^{* *}$} & {$[0.041]^{* *}$} & {$[0.022]^{* *}$} \\
\hline \multirow[t]{2}{*}{ Diabetes } & 0.050 & 0.199 & -0.042 & 0.005 \\
\hline & {$[0.060]$} & {$[0.258]$} & [0.067] & [0.037] \\
\hline Depression, anxiety & -0.707 & -2.464 & -0.360 & -0.121 \\
\hline & {$[0.036]^{* *}$} & {$[0.148]^{* *}$} & {$[0.039]^{* *}$} & {$[0.021]^{* *}$} \\
\hline
\end{tabular}


Alcohol or drug related problems

$\begin{array}{cccc}-0.509 & -0.512 & -0.328 & -0.145 \\ {[0.112]^{* *}} & {[0.470]} & {[0.122]^{* *}} & {[0.067]^{*}} \\ -0.084 & 0.279 & 0.080 & 0.027 \\ {[0.103]} & {[0.452]} & {[0.115]} & {[0.064]} \\ -0.053 & -0.510 & -0.124 & -0.040 \\ {[0.033]} & {[0.137]^{* *}} & {[0.036]^{* *}} & {[0.019]^{*}} \\ -0.104 & 0.084 & -0.338 & -0.178 \\ {[0.049]^{*}} & {[0.202]} & {[0.053]^{* *}} & {[0.029]^{* *}}\end{array}$

Other health states

Health limits daily activities

$\begin{array}{cccc}-0.215 & -1.292 & -0.662 & -0.406 \\ {[0.015]^{* *}} & {[0.070]^{* *}} & {[0.017]^{* *}} & {[0.010]^{* *}} \\ -0.113 & -0.730 & -0.401 & -0.287 \\ {[0.015]^{* *}} & {[0.070]^{* *}} & {[0.017]^{* *}} & {[0.010]^{* *}} \\ -0.162 & -0.223 & -0.388 & -0.252 \\ {[0.044]^{* *}} & {[0.183]} & {[0.048]^{* *}} & {[0.026]^{* *}} \\ -0.113 & -0.730 & -0.401 & -0.287 \\ {[0.015]^{* *}} & {[0.070]^{* *}} & {[0.017]^{* *}} & {[0.010]^{* *}}\end{array}$

Income variables

$\mathrm{Ln}$ (real equivalent household income)

$\begin{array}{cccc}0.014 & -0.048 & -0.008 & -0.004 \\ {[0.006]^{*}} & {[0.030]} & {[0.007]} & {[0.004]} \\ 0.096 & 0.244 & 0.025 & 0.059 \\ {[0.012]^{* *}} & {[0.052]^{* *}} & {[0.013]+} & {[0.007]^{* *}}\end{array}$

\begin{tabular}{lcccc}
\hline Regional fixed effects & Yes & Yes & Yes & Yes \\
Wave fixed effects & Yes & Yes & Yes & Yes \\
Observations & 104537 & 104537 & 104537 & 104537 \\
Individuals & 22169 & 22169 & 22169 & 22169 \\
R-squared & 0.1720 & 0.1989 & 0.3454 & 0.4184 \\
\hline
\end{tabular}

Note: $+<10 \% ; *<5 \% ; * *<1 \%$. LS = life satisfaction $(1=$ very dissatisfied,..., $7=$ very satisfied $)$; IGHQ = inversed GHQ-12 or mental well-being ( 0 = lowest mental well-being, ..., 3 = highest mental well-being); HS = health satisfaction $(1=$ very dissatisfied,..., 7 = very satisfied $)$, SAH = self-assessed health compared to other people of the same age group $(1=$ very poor health, $\ldots, 5=$ excellent health $)$. Standard errors are in parentheses. Control variables include age, age-squared, gender, employment dummies, education dummies, marital status, number of children, regional and wave fixed effects. 


\section{Table 2: Internal Rankings of Health Problems by Well-Being Measures}

\begin{tabular}{lcccc}
\hline Ordinal ranking of health problems & LS & IGHQ & HS & SAH \\
\hline Problems connected with: arms, legs, hand, feet, back, & & & & \\
etc. & 12 & 10 & 7 & 8 \\
Difficulty in seeing (other than needing glasses to read) & 8 & 7 & 12 & 14 \\
Difficulty in hearing & 13 & 12 & 13 & 15 \\
Skin conditions/allergies & 15 & 13 & 15 & 11 \\
Chest/breathing problems, asthma, bronchitis & 10 & 11 & 10 & 9 \\
Heart/blood pressure or blood circulation problems & 11 & 9 & 8 & 7 \\
Stomach/liver/kidneys or digestive problems & 4 & 5 & 5 & 5 \\
Diabetes & 14 & 14 & 9 & 10 \\
Depression, anxiety & 1 & 1 & 2 & 4 \\
Alcohol or drug related problems & 2 & 2 & 6 & 6 \\
Epilepsy & 9 & 15 & 14 & 13 \\
Migraine or frequent headaches & 7 & 6 & 11 & 12 \\
Other health problems not listed & 6 & 8 & 4 & 3 \\
Health limits daily activities & 3 & 3 & 1 & 1 \\
Health limits amount or type of work & 5 & 4 & 3 & 2 \\
\hline Correlation matrix & LS & IGHQ & HS & SAH \\
\hline LS & 1.000 & 0.896 & 0.739 & 0.654 \\
IGHQ & & 1.000 & 0.768 & 0.664 \\
HS & & & 1.000 & 0.936 \\
SAH & & & & 1.000 \\
\hline
\end{tabular}

Note: $\mathrm{LS}=$ life satisfaction $(1=$ very dissatisfied,..., 7 = very satisfied $)$; IGHQ $=$ inversed GHQ-12 or mental well-being $(0=$ lowest mental well-being, $\ldots, 3=$ highest mental well-being $)$; HS $=$ health satisfaction $(1=$ very dissatisfied, $\ldots, 7=$ very satisfied $) ; \mathrm{SAH}=$ self-assessed health compared to other people of the same age group $(1=$ very poor health, $\ldots, 5=$ excellent health $)$. 


\section{Table 4: Shadow Prices of Health Problems and Conditions}

\begin{tabular}{lcccc}
\hline Shadow Prices (SPs) & LS & IGHQ & HS & SAH \\
\hline Problems connected with: arms, legs, hand, feet, back, etc. & $£ 7$ & $£ 54$ & $£ 9.79 \mathrm{E}+06$ & $£ 1,025$ \\
Difficulty in seeing (other than needing glasses to read) & $£ 21$ & $£ 263$ & $£ 3,473$ & $£ 32$ \\
Difficulty in hearing & $£ 6$ & $£ 23$ & $£ 723$ & $£ 28$ \\
Skin conditions/allergies & $£ 5$ & $£ 6$ & $£ 244$ & $£ 358$ \\
Chest/breathing problems, asthma, bronchitis & $£ 13$ & $£ 53$ & $£ 2.87 \mathrm{E}+05$ & $£ 975$ \\
Heart/blood pressure or blood circulation problems & $£ 8$ & $£ 73$ & $£ 5.28 \mathrm{E}+06$ & $£ 1,189$ \\
Stomach/liver/kidneys or digestive problems & $£ 75$ & $£ 4,242$ & $£ 2.33 \mathrm{E}+09$ & $£ 17,344$ \\
Diabetes & $£ 6$ & $£ 3$ & $£ 598,731$ & $£ 913$ \\
Depression, anxiety & $£ 4.14 \mathrm{E}+05$ & $£ 4.12 \mathrm{E}+15$ & $£ 1.46 \mathrm{E}+12$ & $£ 24,476$ \\
Alcohol or drug related problems & $£ 8,284$ & $£ 4.39 \mathrm{E}+05$ & $£ 76,708,735$ & $£ 1,549$ \\
Epilepsy & $£ 20$ & $-£ 5$ & $£ 3.31 \mathrm{E}+02$ & $£ 80$ \\
Migraine or frequent headaches & $£ 28$ & $£ 3,797$ & $£ 15,145$ & $£ 130$ \\
Other health problems not listed & $£ 45$ & $£ 124$ & $£ 1.47 \mathrm{E}+11$ & $£ 63,356$ \\
Health limits daily activities & $£ 289$ & $£ 29,025$ & $£ 2.58 \mathrm{E}+14$ & $£ 4.84 \mathrm{E}+05$ \\
Health limits amount or type of work & $£ 67$ & $£ 21,728$ & $£ 1.75 \mathrm{E}+11$ & $£ 1.22 \mathrm{E}+05$ \\
\hline
\end{tabular}

Note: All figures are in $£ 1,000$ and are calculated based on the sample average real equivalent household income of $£ 10,000$ per annum. 


\section{Table 5: External Rankings of Health Problems By Well-Being Measures}

\begin{tabular}{|c|c|c|c|}
\hline $\begin{array}{c}\text { External } \\
\text { ranking }\end{array}$ & $\begin{array}{l}\text { Internal } \\
\text { ranking }\end{array}$ & Health problems & SPs \\
\hline 1 & 1 & Depression, anxiety (IGHQ) & $£ 4.12 \mathrm{E}+15$ \\
\hline 2 & 1 & Health limits daily activities (HS) & $£ 2.58 \mathrm{E}+14$ \\
\hline 3 & 2 & Depression, anxiety (HS) & $£ 1.46 \mathrm{E}+12$ \\
\hline 4 & 3 & Health limits amount or type of work (HS) & $£ 1.75 \mathrm{E}+11$ \\
\hline 5 & 4 & Other health problems not listed (HS) & $£ 1.47 \mathrm{E}+11$ \\
\hline 6 & 5 & Stomach/liver/kidneys or digestive problems (HS) & $£ 2.33 \mathrm{E}+09$ \\
\hline 7 & 6 & Alcohol or drug related problems (HS) & $£ 7.67 \mathrm{E}+07$ \\
\hline 8 & 7 & Problems connected with: arms, legs, hand, feet, back, etc. (HS) & $£ 9.79 \mathrm{E}+06$ \\
\hline 9 & 8 & Heart/blood pressure or blood circulation problems (HS) & $£ 5.28 \mathrm{E}+06$ \\
\hline 10 & 9 & Diabetes (HS) & $£ 5.99 \mathrm{E}+05$ \\
\hline 11 & 2 & Health limits daily activities (SAH) & $£ 4.84 \mathrm{E}+05$ \\
\hline 12 & 2 & Alcohol or drug related problems (IGHQ) & $£ 4.39 \mathrm{E}+05$ \\
\hline 13 & 1 & Depression, anxiety (LS) & $£ 4.14 \mathrm{E}+05$ \\
\hline 14 & 10 & Chest/breathing problems, asthma, bronchitis (HS) & $£ 2.87 \mathrm{E}+05$ \\
\hline 15 & 2 & Health limits amount or type of work (SAH) & $£ 1.22 \mathrm{E}+05$ \\
\hline 16 & 3 & Other health problems not listed (SAH) & $£ 63,356$ \\
\hline 17 & 3 & Health limits daily activities (IGHQ) & $£ 29,025$ \\
\hline 18 & 4 & Depression, anxiety (SAH) & $£ 24,476$ \\
\hline 19 & 4 & Health limits amount or type of work (IGHQ) & $£ 21,728$ \\
\hline 20 & 5 & Stomach/liver/kidneys or digestive problems (SAH) & $£ 17,344$ \\
\hline 21 & 11 & Migraine or frequent headaches (HS) & $£ 15,145$ \\
\hline 22 & 2 & Alcohol or drug related problems (LS) & $£ 8,284$ \\
\hline 23 & 5 & Stomach/liver/kidneys or digestive problems (IGHQ) & $£ 4,242$ \\
\hline 24 & 6 & Migraine or frequent headaches (IGHQ) & $£ 3,797$ \\
\hline 25 & 12 & Difficulty in seeing (other than needing glasses to read) (HS) & $£ 3,473$ \\
\hline 26 & 6 & Alcohol or drug related problems (SAH) & $£ 1,549$ \\
\hline 27 & 7 & Heart/blood pressure or blood circulation problems (SAH) & $£ 1,189$ \\
\hline 28 & 8 & Problems connected with: arms, legs, hand, feet, back, etc. (SAH) & $£ 1,025$ \\
\hline 29 & 9 & Chest/breathing problems, asthma, bronchitis (SAH) & $£ 975$ \\
\hline 30 & 10 & Diabetes (SAH) & $£ 913$ \\
\hline 31 & 13 & Difficulty in hearing (HS) & $£ 723$ \\
\hline 32 & 11 & Skin conditions/allergies (SAH) & $£ 358$ \\
\hline 33 & 14 & Epilepsy (HS) & $£ 331$ \\
\hline 34 & 3 & Health limits daily activities (LS) & $£ 289$ \\
\hline 35 & 7 & Difficulty in seeing (other than needing glasses to read) (IGHQ) & $£ 263$ \\
\hline 36 & 15 & Skin conditions/allergies (HS) & $£ 244$ \\
\hline 37 & 12 & Migraine or frequent headaches (SAH) & $£ 130$ \\
\hline 38 & 8 & Other health problems not listed (IGHQ) & $£ 124$ \\
\hline 39 & 13 & Epilepsy (SAH) & $£ 80$ \\
\hline 40 & 4 & Stomach/liver/kidneys or digestive problems (LS) & $£ 75$ \\
\hline 41 & 9 & Heart/blood pressure or blood circulation problems (IGHQ) & $£ 73$ \\
\hline 42 & 5 & Health limits amount or type of work (LS) & $£ 67$ \\
\hline 43 & 10 & Problems connected with: arms, legs, hand, feet, back, etc. (IGHQ) & $£ 54$ \\
\hline 44 & 11 & Chest/breathing problems, asthma, bronchitis (IGHQ) & $£ 53$ \\
\hline 45 & 6 & Other health problems not listed (LS) & $£ 45$ \\
\hline 46 & 14 & Difficulty in seeing (other than needing glasses to read) (SAH) & $£ 32$ \\
\hline 47 & 7 & Migraine or frequent headaches (LS) & $£ 28$ \\
\hline
\end{tabular}




$\begin{array}{lclc}48 & 15 & \text { Difficulty in hearing (SAH) } & £ 28 \\ 49 & 12 & \text { Difficulty in hearing (IGHQ) } & £ 23 \\ 50 & 8 & \text { Difficulty in seeing (other than needing glasses to read) (LS) } & £ 21 \\ 51 & 9 & \text { Epilepsy (LS) } & £ 20 \\ 52 & 10 & \text { Chest/breathing problems, asthma, bronchitis (LS) } & £ 13 \\ 53 & 11 & \text { Heart/blood pressure or blood circulation problems (LS) } & £ 8 \\ 54 & 12 & \text { Problems connected with: arms, legs, hand, feet, back, etc. (LS) } & £ 7 \\ 55 & 13 & \text { Difficulty in hearing (LS) } & £ 6 \\ 56 & 14 & \text { Diabetes (LS) } & £ 6 \\ 57 & 13 & \text { Skin conditions/allergies (IGHQ) } & £ 6 \\ 58 & 15 & \text { Skin conditions/allergies (LS) } & £ 5 \\ 59 & 14 & \text { Diabetes (IGHQ) } & £ 3 \\ 60 & 15 & \text { Epilepsy (IGHQ) } & -£ 5\end{array}$

Note: All figures are in $£ 1,000$ and are calculated based on the sample average real equivalent household income of $£ 10,000$ per annum. 